\title{
Bacterial contamination of re-usable laryngoscope blades during the course of daily anaesthetic practice
}

\author{
W Lowman, ${ }^{1}$ MB BCh, MMed, FCPath (SA) (Micro) L Venter, ${ }^{2}$ MB ChB, DA (SA) J Scribante, ${ }^{2}$ MCur \\ ${ }^{1}$ Department of Clinical Microbiology and Infectious Diseases, School of Pathology, University of the Witwatersrand, and Infection Control Services \\ Laboratory, National Health Laboratory Services, Johannesburg \\ ${ }^{2}$ Department of Anaesthesiology, University of the Witwatersrand, Johannesburg
}

Corresponding author: W Lowman (warren.lowman@wits.ac.za)

\begin{abstract}
Background and objectives. Hospital-acquired infections (HAIs) are largely preventable through risk analysis and modification of practice. Anaesthetic practice plays a limited role in the prevention of HAIs, although laryngoscope use and decontamination is an area of concern. We aimed to assess the level of microbial contamination of re-usable laryngoscope blades at a public hospital in South Africa.

Setting. The theatre complex of a secondary-level public hospital in Johannesburg.

Methods. Blades from two different theatres were sampled twice daily, using a standardised technique, over a 2-week period. Samples were quantitatively assessed for microbial contamination, and stratified by area on blade, theatre and time using Fisher's exact test.

Results. A contamination rate of $57.3 \%$ (63/110) was found, with high-level contamination accounting for $22.2 \%$ of these. Common commensals were the most frequently isolated micro-organisms (79.1\%), but important hospital pathogens such as Enterobacter species and Acinetobacter baumannii were isolated from blades with high-level contamination. No significant difference in the level of microbial contamination by area on blade, theatre or time was found $(p<0.05)$.

Conclusions. A combination of sub-optimal decontamination and improper handling of laryngoscopes after decontamination results in significant microbial contamination of re-usable laryngoscope blades. There is an urgent need to review protocols and policies surrounding the use of these blades.

S Afr Med J 2013;103(6):386-389. DOI:10.7196/SAMJ.6385
\end{abstract}

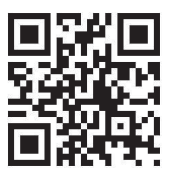

Laryngoscopes are an essential component of anaesthetic practice and are at risk of microbial contamination by both patients and healthcare workers. It is well recognised and documented that laryngoscopes are a potential source of horizontal transmission leading to development of hospital-acquired infections (HAIs). ${ }^{[1,2]}$ Laryngoscope blades and handles have been found to harbour micro-organisms and occult blood, indicating the need for adequate decontamination. ${ }^{[3-5]}$ As a semi-critical item according to the Spaulding classification, sterilisation or high-level disinfection is required. ${ }^{[6]}$ Another option is to use disposable blades. Cost is then an issue, and it does not eliminate the problem of the handle.
There are no consensus guidelines, either globally or nationally, on how best to prevent contamination of laryngoscopes, and surveys have documented varying decontamination practices. ${ }^{[7-9]}$ South Africa (SA) is no different in this regard, although disposable blades are not utilised. To date there are no published data from SA (or Africa) regarding the level of microbial contamination of laryngoscope blades and the effectiveness of decontamination practices. Furthermore, the current literature has not adequately assessed the degree of microbial contamination that occurs during the course of daily practice. The microbial bio-burden may have a direct impact on the level of risk associated with horizontal transmission of micro-organisms and subsequent development of disease. 
This study aimed to assess microbial contamination of laryngoscope blades from the operating theatre of a secondary-level public hospital, permitting insights into the appropriateness and effectiveness of laryngoscope decontamination.

\section{Materials and methods}

This prospective, descriptive study was conducted in two operating theatres of a secondary-level referral hospital in Johannesburg over two separate 1-week periods. Decontaminated re-usable ('readyto-use') blades in the two theatres were sampled twice daily, before the first and after the last endotracheal intubation of the day. Two distinct regions of the blade (areas 1 and 2) that were deemed to have the most contact time with the oral mucosa were selected and sampled separately. The blades were sampled with sterile swabs using a standardised rolling technique, from point $\mathrm{A}$ to $\mathrm{B}$ to $\mathrm{C}$, and from point $\mathrm{D}$ to $\mathrm{E}$ to $\mathrm{D}$ for areas 1 and 2, respectively (Fig. 1). The tips of the swabs were then immersed in the $1 / 4$ Ringer's lactate transport medium used to moisten the swabs prior to sampling, and then stored and transported to the laboratory at $4^{\circ} \mathrm{C}$ on the same day.

Upon receipt of samples in the laboratory $100 \mu \mathrm{l}$ of the transport medium (containing the swab) was used to inoculate a blood agar

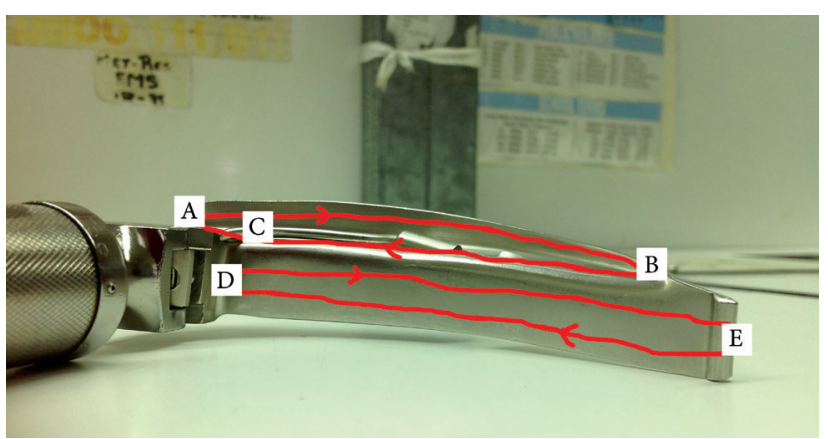

Fig. 1. Sampling strategy and areas $1(A, B, C)$ and $2(D, E)$ of laryngoscope blade. plate (BAP) which was then incubated aerobically for 48 hours. After 48 hours' incubation, colonies of micro-organisms were counted and then identified using standard microbiological methods. ${ }^{[10]} \mathrm{A}$ sample was considered positive if there was any microbial growth on the BAP. A colony count of $>300$ colony-forming units (CFU)/ $\mathrm{ml}$ was considered high-level contamination, $100-300 \mathrm{CFU} /$ $\mathrm{ml}$ intermediate-level contamination, and $<100 \mathrm{CFU} / \mathrm{ml}$ lowlevel contamination. A sample was considered negative and not contaminated if no colonies were present on the BAP after 48 hours' incubation.

\section{Statistical analysis}

Categorical variables such as type of micro-organism and degree of contamination are presented as frequencies and/or percentages. Comparative analysis of the degree of contamination by area on blade, sampling time and theatre was performed using Fisher's exact test, with a $p$-value of $<0.05$ considered significant.

\section{Results}

A total of 112 samples were taken over the 2-week period of sampling. Two samples were rejected and 110 samples included in the analysis. There was a contamination rate of $57.3 \%$ $(63 / 110)$, with common commensals accounting for the majority of micro-organisms isolated (79.1\%). High-level contamination of 14 samples was detected, and included nosocomial pathogens such as Enterobacter species, (3 samples) and Acinetobacter baumannii (1 sample). The different types of micro-organisms and their relative contamination levels are presented in Table 1. In comparing the level of contamination by area on blade, time of day, theatre and week, no statistically significant differences were found (Table 2).

\section{Discussion}

This study highlights a significant level of bacterial contamination of re-usable laryngoscope blades. This finding confirms that current decontamination and disinfection practices are suboptimal, placing

Table 1. Types of micro-organisms isolated and degree of contamination associated with each type

\begin{tabular}{|c|c|c|c|c|}
\hline Micro-organisms cultured & $\begin{array}{l}\text { Samples with } \\
\text { positive growth } \\
n(\%)\end{array}$ & $\begin{array}{l}\text { Samples with low-level } \\
(1 \text { - } 99 \mathrm{CFU} / \mathrm{ml}) \\
\text { contamination } \\
n(\%)\end{array}$ & $\begin{array}{l}\text { Samples with intermediate- } \\
\text { level }(100-300 \mathrm{CFU} / \mathrm{ml}) \\
\text { contamination } \\
n(\%)\end{array}$ & $\begin{array}{l}\text { Samples with high- } \\
\text { level }(>300 \mathrm{CFU} / \mathrm{ml}) \\
\text { contamination } \\
n(\%)\end{array}$ \\
\hline Diphtheroids* & $35(55.5)$ & 25(39.7) & $2(3.2)$ & $8(12.7)$ \\
\hline Arcanobacterium haemolyticum & $2(3.1)$ & $6(9.5)$ & 0 & 0 \\
\hline Viridans streptococci & $4(6.3)$ & $2(3.2)$ & $1(1.6)$ & $1(1.6)$ \\
\hline Micrococcus spp. & $7(11.1)$ & $7(11.1)$ & 0 & 0 \\
\hline \multicolumn{5}{|l|}{ Coagulase-negative staphylococci } \\
\hline Total & $26(40.6)$ & $25(39.7)$ & 0 & $1(1.6)$ \\
\hline Staphylococcus epidermidis & $25(39.7)$ & $24(38.1)$ & 0 & $1(1.6)$ \\
\hline S. auricularis & $1(0.9)$ & $1(1.6)$ & 0 & 0 \\
\hline Enterobacter spp. & $4(6.3)$ & $1(1.6)$ & 0 & $3(4.8)$ \\
\hline Acinetobacter baumannii & $6(9.5)$ & $3(4.8)$ & $2(3.2)$ & $1(1.6)$ \\
\hline Candida albicans & $1(0.9)$ & $1(1.6)$ & 0 & 0 \\
\hline Bacillus spp. & $6(9.5)$ & $6(9.5)$ & 0 & 0 \\
\hline
\end{tabular}


Table 2. Stratification of blade contamination by sampling variables

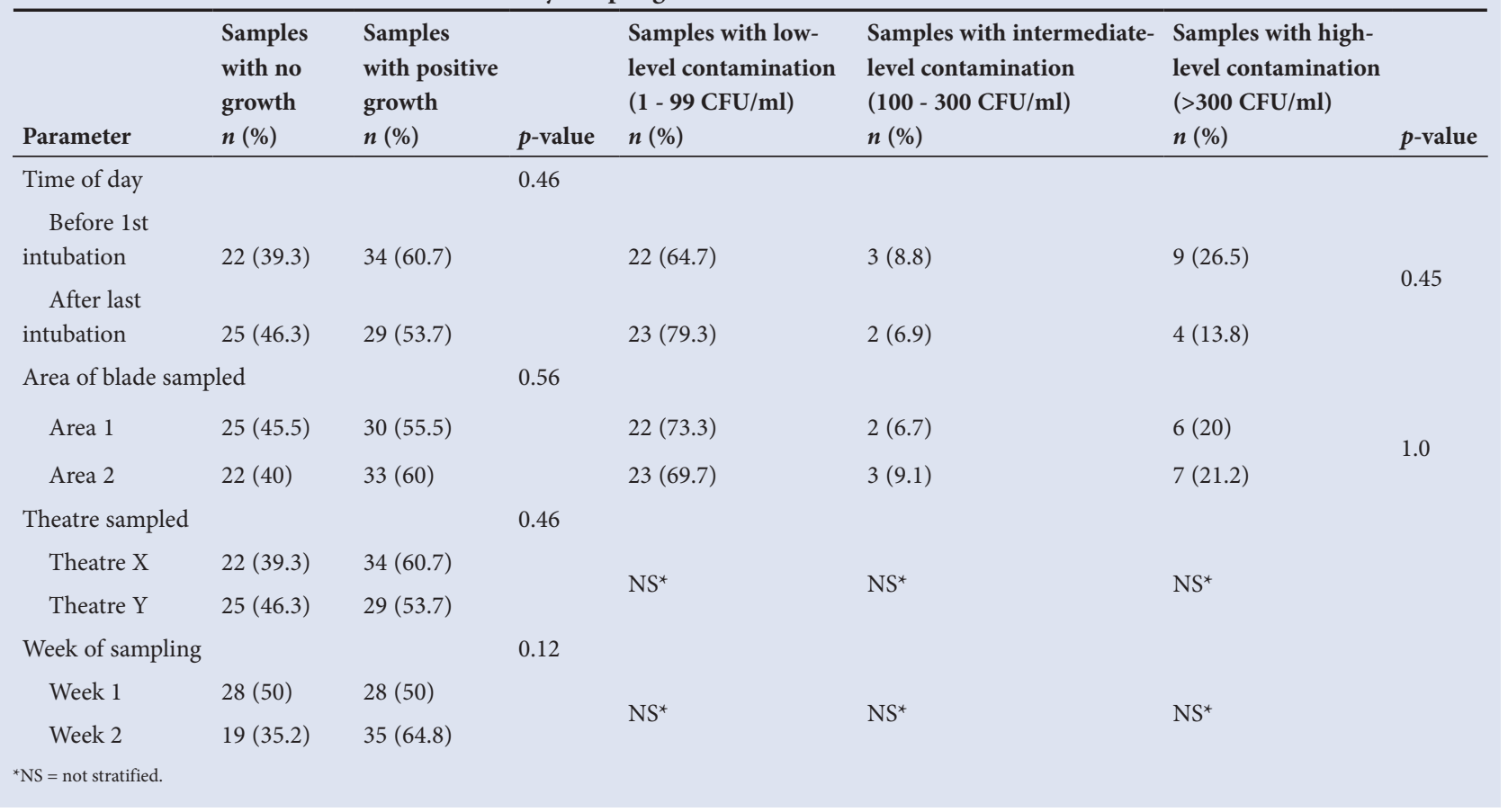

patients at potential risk of acquiring HAIs through horizontal transmission of micro-organisms.

The types of micro-organisms isolated are of interest from a contamination source perspective, and consistent with those previously reported. ${ }^{[5,11]}$ The predominance of diptheroids reflects the normal flora of the oral cavity, as does isolation of viridans streptococci and Arcanobacterium haemolyticum. However, the large number of coagulase-negative staphylococci and micrococci isolated may suggest contamination by personnel, as these are common skin commensals. We also aimed to quantitatively assess the level of microbial contamination, as this may influence infectious risk to other patients, and as an indirect measure of the adequacy of decontamination. High-level contamination was found in more than $22 \%$ of all positive samples, suggesting a serious breach in the decontamination process. Whether these blades were cleaned with a disinfectant at all, or were compromised after cleaning, is unknown but indicates an urgent need for review of the process.

The isolation of A. baumannii and Enterobacter species on 6 and 4 samples, respectively, is of particular concern given that these are typical hospital pathogens and, with high-level contamination of 4 of the blades, there is a significant risk of nosocomial transmission. Whether contamination of the blades derived from theatre personnel's hands or patients' oral cavities remains speculative. Suboptimal disinfection and handling of blades is clearly demonstrated. The point at which contamination primarily occurs is an important issue, as it will have direct bearing on any intervention.

The non-significant difference in contamination found by time, area of blade, theatre and week sampled indicates that the poor decontamination of blades is a consistent phenomenon and reflects inadequate daily practice in theatre. Although there was the possibility of a Hawthorne effect, ${ }^{[12]}$ and towards the end of the first week it appeared that samples were less contaminated, the second week of sampling demonstrated higher levels of contamination despite staff being aware of the study.
According to guidelines, laryngoscope blades should be decontaminated using either a high-level disinfectant or sterilisation, which is consistent with the device being classified as a semicritical item. ${ }^{[6]}$ In this study, the theatre complex used a low-level disinfectant (Bioscrub) for soaking and scrubbing, with subsequent rinsing under tap water. Blades were then dried with non-sterile paper towel. This practice is widely employed throughout the country (personal communication, L Visser, 2011). Surveys have corroborated the diversity of methods and disinfectants used, as well as non-compliance with recommendations for high-level disinfection as a minimum standard. ${ }^{[8,9]}$ However, the choice of high-level disinfection or sterilisation is only one aspect of ensuring appropriate decontamination of blades, and appropriate handling of the blades after decontamination is critical to prevent contamination by theatre personnel. A number of studies have highlighted contamination of laryngoscope handles and the very real threat of cross-contamination of handle to blade. ${ }^{[13,14]}$ Hand hygiene, appropriate use of gloves and maintenance of aseptic technique are of paramount importance. Single-use, disposable blades offer a solution but are costly and not feasible in resource-limited settings. A cost-effectiveness analysis with respect to the risk of acquiring an HAI would be needed to justify their routine use.

Although there are reports of outbreaks linked to contaminated laryngoscopes, ${ }^{[7]}$ it often remains difficult to prove conclusively that contaminated laryngoscope blades are responsible for an outbreak or for horizontal transmission of infection. Moreover, no studies have demonstrated a reduced risk of HAI through a change in laryngoscope decontamination practice. This lack of evidence is an obstacle to a change in practice. As pointed out by Muscarella, the lack of consensus guidelines and statements from authoritative bodies regarding the reprocessing of laryngoscope blades has created confusion and uncertainty as to what constitutes a minimum standard. ${ }^{[7]}$ The fact remains that there is a potential risk to patients, and efforts to minimise this risk must be enforced. Other infectious agents such as prions and blood-borne viruses have been shown to be an additional potential risk. ${ }^{[3,15]}$ 


\section{RESEARCH}

This study was limited to a single hospital theatre complex and therefore may not be generalisable. It was limited to the identification of aerobic bacterial and fungal micro-organisms, so the degree of contamination with other infectious agents is unknown. The exact point at which most contamination occurs could not be identified, but may have been inappropriate decontamination of the blades after use (with contamination primarily from the patient's oral cavity), or poor handling of blades after decontamination, with contamination primarily by personnel. It is likely that contamination occurs at both these points, although further studies are needed to confirm this.

In summary, this study highlights the fact that improved and standardised methods of decontamination of laryngoscopes need to be instituted in conjunction with improved infection prevention practices by staff handling the blades.

Acknowledgments. We thank the staff of the Infection Control Services Laboratory, National Health Laboratory Services, for their commitment to the study and dedication to the processing of samples. The paper was presented at the South African Society of Anaesthesiologists Congress, 28 February - 2 March 2011.

Conflict of interests. The study was funded by a Faculty Research Committee grant from the University of the Witwatersrand.

Ethical approval. An ethical waiver was obtained from the University of the Witwatersrand Ethics Committee.

\section{References}

1. Cullen MM, Trail A, Robinson M, Keaney M, Chadwick PR. Serratia marcescens outbreak in neonatal intensive care unit prompting review of decontamination of laryngoscopes. J Hosp Infect 2005;59(1):68-70. [http://dx.doi.org/10.1016/j.jhin.2004.08.003]

2. Foweraker JE. The laryngoscope as a potential source of cross-infection. J Hosp Infect 1995;29(4):315-316.

3. Phillips RA, Monaghan WP. Incidence of visible and occult blood on laryngoscope blades and handles. AANA J 1997;65(3):241-246.

4. Morell RC, Ririe D, James RL, Crews DA, Huffstetler K. A survey of laryngoscope contamination at a university and a community hospital. Anesthesiology 1994;80(4):960. [http://dx.doi. org /10.1097/00000542-199404000-00038]

5. Ballin MS, McCluskey A, Maxwell S, Spilsbury S. Contamination of laryngoscopes. Anaesthesia 1999;54(11):1115-1116. [http://dx.doi.org/10.1046/j.1365-2044.1999.01178.x]

6. Spaulding EH. Chemical disinfection of medical and surgical materials. In: Lawrence CB, Block SS, 6. Spaulding EH. Chemical disinfection of medical and surgical materials. In: Lawren
eds. Disinfection, Sterilization and Preservation. Philadelphia: Lea \& Febiger, 1968.

7. Muscarella LF. Reassessment of the risk of healthcare-acquired infection during rigid laryngoscopy. Hosp Infect 2008;68(2):101-107. [http://dx.doi.org/10.1016/j.jhin.2007.11.004]

8. Esler MD, Baines LC, Wilkinson DJ, Langford RM. Decontamination of laryngoscopes: survey of national practice. Anaesthesia 1999;54(6):587-592. [http://dx.doi.org/10.1046/j.13652044.1999.00755.x]

9. Morgan DR, Lamont T], Dawson JD, Booth C. Decontamination of instruments and control of cross infection in general practice. BMJ 1990;300:1379-1380. [http://dx.doi.org/10.1136/bmj.300.6736.1379]

10. Murray PR, Baron EJ, Jorgensen JH, Landry ML, Pfaller MA, eds. Manual of Clinical Microbiology. 7t ed. Washington, DC: ASM Press, 2007.

11. Roberts RB. Cleaning the laryngoscope blade. Can Anaesth Soc J 1973;20(2):241-244. [http://dx.doi. org/10.1007/BF03027213]

12. Gale EA. The Hawthorne studies - a fable for our times? QJM 2004;97(7):439-449. [http://dx.doi. org/10.1093/gimed/hch070]

13. Call TR, Auerbach FJ, Riddell SW, et al. Nosocomial contamination of laryngoscope handles: challengin current guidelines. Anesth Analg 2009;109(2):479-483. [http://dx.doi.org/10.1213/ane.0b013e3181ac1080] current guidelines. Anesth Analg 2009;109(2):479-483. [http://dx.doi.org/10.1213/ane.0b013e3181ac1080]
Williams D, Dingley J, Jones C, Berry N. Contamination of laryngoscope handles. J Hosp Infect 4. Williams D, Dingley J, Jones C, Berry N. Contamination of lar
2010;74(2):123-128. [http://dx.doi.org/10.1016/j.jhin.2009.09.015]

15. Hirsch N, Beckett A, Collinge J, Scaravilli F, Tabrizi S, Berry S. Lymphocyte contamination of laryngoscope blades - a possible vector for transmission of variant Creutzfeldt-Jakob disease Anaesthesia 2005;60(7):664-667. [http://dx.doi.org/10.1111/j.1365-2044.2005.04221.x] 